\title{
A Field Study for Sustainable Community Empowerment through Appropriate Technology of Water Purification and the Concept of Feces Standard Money in Hatphain Village, Lao PDR
}

\author{
Huijin $\mathrm{Heo}^{1}$, Mi-Jin Choi ${ }^{1, \dagger}$, Tae Hyug $\mathrm{Im}^{2}$, Jaeweon Cho ${ }^{1, \dagger}$ \\ ${ }^{1}$ School of Urban and Environmental Engineering, Ulsan National Institute of Science and Technology, \\ Ulsan 44919, Republic of Korea \\ ${ }^{2}$ Vientiane Korean Academy, Somvang Village 19, Sisattanak District, Vientiane Capital, LAO P.D.R.
}

\begin{abstract}
The application of appropriate technologies in a developing country is an opportunity to introduce green technology which may lead people to imagine a better life. This point is at the intersection of appropriate technology and sustainable development. This research focuses on Hatphain village where there is no clean water, sewage system, or power lines. Two environmental technologies (an unpowered water purification system, Ongdalsaem and an eco-toilet system, BeeVi toilet) were introduced, based on the concepts of the environmental self- sustainable village and feces Standard Money (fSM). We found that the Ongdalsaem was effective in reducing the concentration of nitrogen and lead in the water in Hatphain. The BeeVi water-free toilet was installed, allowing urine and feces to be separated and used as compost. We strived to spread ideas of sustainability using new eco-circulation experiences and encouraging learning about environmental technology through practical and playing facilities that residents managed themselves.
\end{abstract}

KEYWORDS: BeeVi Toilet, Feces Standard Money (fSM), Manure, Ongdalsaem Water Purification System, Sustainable village

\section{Introduction}

Habits are naturally formed in our everyday life and are difficult to change via unilateral education. For example, these days we cannot imagine life without mobile phones, the internet, or even without the great invention of the flushing toilet. Therefore, to implement natural and gradual changes, it is necessary to properly set development goals and directions at the beginning stages of a project. The development should not only help make life in a community more convenient, but it should also consider sustainability towards a better future. Applying appropriate technologies in a developing country can be an opportunity to introduce green technology to the region and give people a chance to imagine a better life. Thus, appropriate technology is connected to sustainable development.

\footnotetext{
To whom correspondence should be addressed.

E-mail:cmj111@unist.ac.kr, jaeweoncho@unist.ac.kr

Received: 5 October 2021, Revised: 27 October 2021,

Accepted: 27 October 2021
}

Especially, there is a general lack of infrastructure for water treatment and sanitation in developing countries. Therefore, sustainable development based on appropriate technologies has been applied to water and sanitation sectors and these are closely related to the lives and survival of local people (Murphy et al., 2009; Patnaik \& Bhowmick, 2019; Shin et al., 2019; Sorlini et al., 2015). In the case of water, LifeStraw, a well-known appropriate technology, produces potable safe water by filtration (Frandsen, 2005). Peepoo bag is an example of enhancement in the sanitation sector (Vinnerås et al., 2009). It is a disposable and biodegradable plastic bag in which one can excrete privately and safely. After excretion, the bag and excreta become fertilizer. Moser lamp was invented using plastic bottles for stable light supply during the night without electricity (Jakariya et al., 2018). The appropriate technology for a given community should be carefully designed to minimize its impact on the surrounding environment and society.

Our research team identified self-sustainable development, 
appropriate technology, and the participation of residents as the most important factors (Bamberger, 1991; Davidson et al., 2007). Therefore, the plan drew on environmental engineering and social engineering simultaneously. However, simply installing new technology is not sufficient for a self-sustainable application. Rather, the development plan should combine technology with a philosophy to gain support and agreement from the residents. Through this philosophy, a development project can become resonant for the community and therefore create more sustained development in the community.

In this study, Hatphain village, Lao PDR (part of the Vientiane Capital Province) is the research context. Hatphain village is located $50 \mathrm{~km}$ south of downtown Vientiane and is surrounded by the Nam Ngum River. This village lacks clean water, sanitation, and electricity infrastructure. Therefore, issues related to potable water and the sewage system are severe and many Hatphain residents relieve themselves in the woods. Potable water is obtained from wells but it is not safe to drink directly due to components of lime and heavy metals.

This research introduced two environmental technologies to Hatphain, Lao PDR: an unpowered water purification system, Ongdalsaem and an eco-toilet system, BeeVi toilet. These technologies were underlined by two concepts which are the environmental self-sustainable village and feces Standard Money (fSM) (Cho, 2017). The first purpose of this study was to provide a clean and safe water supply along with an easyto-use water purification system for residents in Hatphain village. The second purpose was to install an eco-toilet that was connected to composting and farming in the area. Finally, the concept of fSM was introduced to draw interest and spontaneity from the residents. The overall technical installment was accompanied by an ecological education program run by a local activist. Education material suitable for children in Hatphain was provided by our research team.

\section{Materials and Methods}

\section{Preliminary site investigation.}

Hatphain village is in Xythani district of Vientiane capital province, the largest district in Lao PDR. Although it is only $50 \mathrm{~km}$ from the center of Vientiane, the infrastructure development and environment are not comparable with Vientiane city, and it is slower in progress than other countryside villages. The government-supported development is focused on the central area of Vientiane and the provincial cities due to budgetary limitations. In addition, Hatphain is geographically isolated by the Nam Ngum River and the surrounding mountains, so exchanges and communications with Vientiane city are rare.

The issues related to water and sewage infrastructure are extreme in the Hatphain village. There is no water pipeline, so residential water can only be accessed by digging a well at each house. However, this water is not suitable to drink directly because of lime and heavy metals, and pathogenic microorganism originated from feces. In terms of toilets, some people use a squat toilet in their house, but other poor families still go to the forest to defecate.

The new technologies were applied at Hatphain elementary school which is the only educational facility in the village. They operate in a harsh environment. There were only 2 public toilets even though there are four teachers and 62 students. However, it was only possible to use one toilet because the other toilet was broken and unhygienic. A private business was given the opportunity to make a well for the school four years ago, but there are no storage tanks or pipelines to the toilets. Thus, it had low practical usability for the children. The government built a classroom building, but it is not equipped with electricity or even simple fans due to budgetary constraints. Therefore, it is hard to bear extremely hot weather at the school. Due to these poor facilities, student attendance is low.

\section{Water purification system design}

\subsection{Water quality analysis for raw water source selection.}

Before designing the Ongdalsaem water purification system, water quality analysis was conducted for raw water source selection, which is based on parameters selected from the quality standards for potable water of the Korean Ministry of Environment (Table A1). Dissolved organic carbon (DOC), total nitrogen (TN), UV absorbance at $254 \mathrm{~nm}\left(\mathrm{UVA}_{254 \mathrm{~nm}}\right)$, and specific $\mathrm{UVA}_{254 \mathrm{~nm}}$ (SUVA) were measured to observe the amount of organic matter in the water sample, although these parameters are not included in the standards. Specifically, we considered that ammonium-nitrogen $\left(\mathrm{NH}_{4}{ }^{+}-\mathrm{N}\right)$, nitrate-nitrogen $\left(\mathrm{NO}_{3}^{-}-\mathrm{N}\right)$, E. coli, metals, and heavy metals were important factors that should influence the raw water source selection because these frequently cause problems associated with drinking water such as Diarrhea, Schistosomiasis anemia, 
cancer risk, and skin damage in developing countries (Chowdhury et al., 2016).

$\mathrm{pH}$ was measured in situ by Waterproof Double Junction pHTestr 30 (Oakton instruments, USA). In the lab, $\mathrm{pH}$ and conductivity were measured by Orion 3 Star $\mathrm{pH}$ portable (Thermo Scientific Inc., USA) and Conductivity portable (Thermo Scientific Inc., USA), respectively. After filtering samples with $0.45 \mu \mathrm{m}$ syringe filters (25CS045AS, Advantec, Japan), TOC/TN and $\mathrm{UVA}_{254 \mathrm{~nm}}$ were measured using the TOC/TN analyzer (TOC-VCPH/TNM-1, Shimadzu, Japan) and UV-vis spectrophotometer (UV-1601, Shimadzu, Japan), respectively. Heavy metals (except for $\mathrm{Hg}$ ) were analyzed by an inductively coupled plasma-mass spectrometer (iCAP Q, Thermo Scientific Inc., USA), while Hg was determined by the atomic absorption spectrometer (240AA, Varian Inc., USA). All the metals and heavy metals were analyzed according to standard methods for the examination of water and wastewater of the Korean Ministry of Environment.

$E$. coli is an important parameter because it greatly influences the occurrence of waterborne diseases. However, it was difficult to analyze in situ, so this analysis was conducted in Korea. Therefore, the analysis results in Korea are unreliable because $E$. coli growth in water is influenced by storage period and temperature from the time of sampling at Lao PDR to the time of analysis in Korea. Therefore, the results were used as reference information. The analysis of $E$. coli was based on standard methods for the examination of water and wastewater of the Korean Ministry of Environment.

The safest water source was chosen by comparing the analysis results and the quality standards for potable water of the Korean Ministry of Environment. Preliminary water quality analyses were conducted twice for the selection. Besides, additional water quality analyses were conducted twice after the installation of the water purification system to verify the system.

\subsection{Ongdalsaem water purification system design}

The Ongdalsaem water purification system was designed based on the raw water quality of the selected water source. The capacity of the water purifier was set to $200 \mathrm{~L}$ and a raw water storage tank was included for a smooth supply of raw water to the water purifier. The Ongdalsaem is designed to purify water with a membrane rather than chemicals. The membranes used are A4 sized gravity-driven membranes (X crossing, AMTS, Korea), which can function through water pressure only and so, do not require a pump. The detailed specifications of the membrane are featured in Table A2.

Raw water in the storage tank flows through a pretreatment process, followed by membrane filtration. The pretreatment process was added to remove some turbidity before the raw water entered the water purifier because the durability of the gravity-driven membrane is affected by the turbidity of raw water. The pretreatment process was based on the elementary processes of water treatment which are screening, sedimentation, filtration, and adsorption. To achieve these processes, gravel, charcoal, and pieces of hemp cloth filled an acrylic chamber. All components were composed of materials that are locally available.

\section{Toilet design}

Conventional squat toilets are mainly used in Hatphain village. The poorest households do not have toilets, so they go into the forest, dig a hole, and excrete in the ground. This form of excretion causes environmental and hygiene issues and people, especially children, can be exposed to infectious diseases. As previously described, there was only one working toilet in Hatphain elementary school. Therefore, our research team tried to design a field applicable and eco-friendly BeeVi toilet for the students and teachers of the elementary school.

The new 2-storey toilet building was separated from the main classroom building. The second floor is the actual toilet and handbasin while the first floor is used as a compost shed. The BeeVi toilet does not use water, unlike the existing flushing toilet in the school, and it separates urine and feces. The feces gather in the wagon under the toilet, and sawdust should be periodically spread on the feces to help air circulation. When the wagon is full, the feces and sawdust go to the composting area. Urine, separated from feces, is also transformed into liquid manure. This design was made specifically for Hatphain village where there is a lack of potable water and no sewage system.

\section{Results and Discussion}

\section{Ongdalsaem water purification system}

\subsection{Preliminary water quality analysis results and selection of raw water source.}



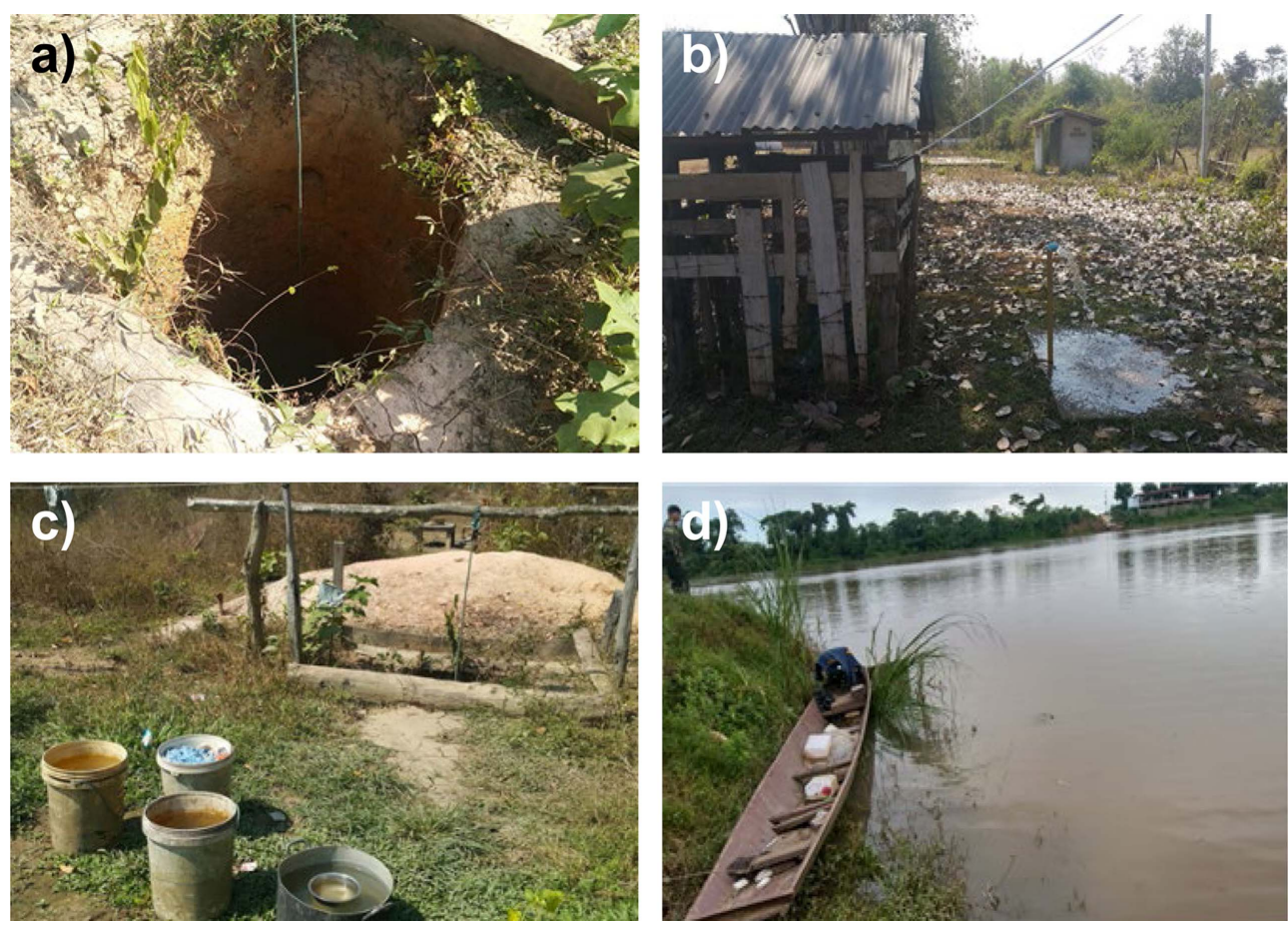

Figure 1. Photographs showing sampling sites. (a) W1 = Hatphain village well, (b) W2 = Hatphain elementary school well, (c) W3 = House well, and (d) R1 = Nam Ngum River

To find the secure raw water source, water quality analyses were conducted with various water samples in April 2017 (Figure 1). Hatphain village well (W1, $10 \mathrm{~m}$ depth) and another well in the Hatphain elementary school (W2, $40 \mathrm{~m}$ depth) were the sources for the first water quality analysis (Table 1). Water samples from both $\mathrm{W} 1$ and $\mathrm{W} 2$ showed fairly low $\mathrm{pH}$ levels of 4.36 and 5.82, respectively compared to the quality standards for potable water $(\mathrm{pH} 5.8 \sim 8.5)$. While organic matter was detected at a low level, the $\mathrm{NH}_{4}{ }^{+}-\mathrm{N}(1.58 \mathrm{mg} / \mathrm{L})$ and $\mathrm{NO}_{3}{ }^{-} \mathrm{-N}(32.45 \mathrm{mg} / \mathrm{L})$ of $\mathrm{W} 1$ exceeded the standards $(0.5$ $\mathrm{mg} / \mathrm{L}$ and $10 \mathrm{mg} / \mathrm{L}$, respectively), which may be caused by fertilizers or excreta and exacerbated by the well's relatively shallow depth. Unfortunately, a higher concentration of $\mathrm{Pb}$ was detected in both $\mathrm{W} 1(0.02 \mathrm{mg} / \mathrm{L})$ and $\mathrm{W} 2(0.05 \mathrm{mg} / \mathrm{L})$ than is standardly acceptable $(0.01 \mathrm{mg} / \mathrm{L})$. Therefore, it was decided both W1 and W2 were not suitable to drink and could not be used as a raw water source. We needed to find other sources that were less polluted.

Another trial to find an appropriate water source was conducted in May 2017. The raw water source options were W3, a well of a residence (W3, $9 \mathrm{~m}$ depth), and a tributary of Nam Ngum River (R1) near the village (Table 1). In the first analysis, the long delivery time from the sampling site in Hatphain village to the lab in Korea was thought to affect the $\mathrm{pH}$ level results, so in-situ $\mathrm{pH}$ measurement was added. In the W2 sample, $\mathrm{Pb}(0.04 \mathrm{mg} / \mathrm{L})$ was still measured above the standards $(0.01 \mathrm{mg} / \mathrm{L})$, so W2 was excluded as a possible raw water source. In the case of $\mathrm{W} 3$, the $\mathrm{pH}$ at the sampling site $(\mathrm{pH} 5.73)$ was close to the standard, although not within the standard range. $\mathrm{NO}_{3}^{-}-\mathrm{N}(9.59 \mathrm{mg} / \mathrm{L})$ was detected as a concentration less than the standard $(10 \mathrm{mg} / \mathrm{L})$, so W3 was not considered a stable raw water source. R1 measured low DOC, TN, and $\mathrm{NO}_{3}{ }^{-}-\mathrm{N}$ concentrations. In addition, $\mathrm{NH}_{4}{ }^{+}-\mathrm{N}$ and heavy metals were not detected, therefore R1 seemed to be the most appropriate raw water source for the Ongdalsaem water purification system. However, the turbidity of R1 significantly increased with the onset of the rainy season in July of 2017. When using R1 as a raw water source, it was expected that excessive sediment accumulation inside the raw water storage tank would cause operational problems in the Ongdalsaem. Therefore, W3 was finally chosen as the raw water source as an alternative. 
Table 1. Preliminary water quality analysis for raw water source selection in April and May of 2017; W1 = Village well, W2 = Elementary school well, W3 = House well, and R1 = Nam Ngum River

\begin{tabular}{|c|c|c|c|c|c|c|}
\hline \multirow{2}{*}{ Parameters } & \multicolumn{2}{|c|}{$1^{\text {st }}$ analysis } & \multicolumn{3}{|c|}{$2^{\text {nd }}$ analysis } & \multirow{2}{*}{$\begin{array}{c}\text { Drinking Water } \\
\text { Standard }^{\mathrm{a}}\end{array}$} \\
\hline & W1 & W2 & W2 & W3 & R1 & \\
\hline Well depth (m) & 10 & 40 & 40 & 9 & - & - \\
\hline DOC (mg C/L) & 0.40 & 0.40 & 0.24 & 0.32 & 0.96 & - \\
\hline $\mathrm{TN}(\mathrm{mg} \mathrm{N} / \mathrm{L})$ & 9.04 & 0.32 & 0.32 & 2.36 & 0.24 & - \\
\hline UVA254nm & 0.0052 & 0.0019 & 0.0017 & 0.0034 & 0.0276 & - \\
\hline SUVA & 1.28 & 0.49 & 0.71 & 1.04 & 2.89 & - \\
\hline Conductivity $(\mu \mathrm{S} / \mathrm{cm})$ & 139.4 & 23.35 & 32.7 & 49.4 & 124.7 & - \\
\hline $\mathrm{pH}$ in field & - & - & $5.82^{\dagger}$ & $5.35^{\dagger}$ & 7.56 & $5.8-8.5$ \\
\hline $\mathrm{pH}$ at lab & $4.36^{\dagger}$ & $5.41^{\dagger}$ & $6.34^{\dagger}$ & $5.73^{\dagger}$ & 8.22 & $5.8-8.5$ \\
\hline $\mathrm{NH}_{4}^{+}-\mathrm{N}(\mathrm{mg} / \mathrm{L})$ & $1.58^{\dagger}$ & N.D. & N.D. & N.D. & N.D. & $<0.5 \mathrm{mg} / \mathrm{L}$ \\
\hline $\mathrm{NO}_{3}{ }^{-}-\mathrm{N}(\mathrm{mg} / \mathrm{L})$ & $32.45^{\dagger}$ & 0.89 & 1.35 & 9.59 & 0.63 & $<10 \mathrm{mg} / \mathrm{L}$ \\
\hline $\mathrm{Pb}(\mathrm{mg} / \mathrm{L})$ & $\mathbf{0 . 0 2}^{\dagger}$ & $0.05^{\dagger}$ & $\mathbf{0 . 0 4}^{\dagger}$ & N.D. & N.D. & $<0.01 \mathrm{mg} / \mathrm{L}$ \\
\hline As $(\mathrm{mg} / \mathrm{L})$ & N.D. & N.D. & N.D. & N.D. & N.D. & $<0.01 \mathrm{mg} / \mathrm{L}$ \\
\hline $\mathrm{Hg}(\mathrm{mg} / \mathrm{L})$ & N.D. & N.D. & N.D. & N.D. & N.D. & $<0.001 \mathrm{mg} / \mathrm{L}$ \\
\hline $\mathrm{Cr}(\mathrm{mg} / \mathrm{L})$ & N.D. & N.D. & N.D. & N.D. & N.D. & $<0.05 \mathrm{mg} / \mathrm{L}$ \\
\hline $\mathrm{Cd}(\mathrm{mg} / \mathrm{L})$ & N.D. & N.D. & N.D. & N.D. & N.D. & $<0.005 \mathrm{mg} / \mathrm{L}$ \\
\hline $\mathrm{Cu}(\mathrm{mg} / \mathrm{L})$ & N.D. & 0.05 & 0.02 & N.D. & N.D. & $<1 \mathrm{mg} / \mathrm{L}$ \\
\hline $\mathrm{Zn}(\mathrm{mg} / \mathrm{L})$ & N.D. & 0.03 & 0.02 & 0.02 & N.D. & $<3 \mathrm{mg} / \mathrm{L}$ \\
\hline $\mathrm{Fe}(\mathrm{mg} / \mathrm{L})$ & N.D. & N.D. & N.D. & N.D. & N.D. & $<0.3 \mathrm{mg} / \mathrm{L}$ \\
\hline $\mathrm{Mn}(\mathrm{mg} / \mathrm{L})$ & 0.25 & 0.03 & 0.03 & 0.15 & N.D. & $<0.3 \mathrm{mg} / \mathrm{L}$ \\
\hline $\mathrm{Al}(\mathrm{mg} / \mathrm{L})$ & $1.1^{\dagger}$ & 0.02 & N.D. & 0.11 & N.D. & $<0.2 \mathrm{mg} / \mathrm{L}$ \\
\hline
\end{tabular}

${ }^{\mathrm{a}}$ Korean Ministry of Environment

- means not applicable.

N.D. means not detected.

"means unsuitable according to the standards for potable water.

\subsection{Installation of Ongdalsaem water purification system and maintenance training}

The raw water storage tank and pretreatment system were installed outside the elementary school building, and the water purifier was installed inside the building for easy maintenance (Table 2). The water purifier was made by connecting six A4sized gravity-driven membranes inside the $200 \mathrm{~L}$ water tank to a faucet with ca. $500 \mathrm{~mL} / \mathrm{min}$ at the time of the installation (2017.7.20).

The Ongdalsaem water purification system supplied fresh water to about 624 people not only including Hatphain village residents but also neighboring students and their families. To continuously provide safe drinking water, a management manual was prepared and delivered, and the elementary school teacher was designated as the water system manager in charge. Furthermore, a local activist collaborated in maintenance and user education (Figure 2).

\subsection{Water quality analysis after installation}

After the installation of the Ongdalsaem water purification system, water quality analyses were conducted twice, once in September 2017 and once in January 2018. Raw water, initially treated water after pretreatment and final treated water after membrane filtration were analyzed with similar parameters to the preliminary analysis.

At the first post-installation water analysis, most parameters measured lower than the quality standards for potable water (Table 3). However, $\mathrm{Pb}$ was detected in raw water (W3-R) and first treated water (W3-1) above the standard showing 0.022 $\mathrm{mg} / \mathrm{L}$ and $0.017 \mathrm{mg} / \mathrm{L}$, respectively. Fortunately, $\mathrm{Pb}$ was not detected in the final treated water (W3-F).

However, there was an insufficient quantity of water in W3 
Table 2. Processes showing the installation of the Ongdalsaem water purification system

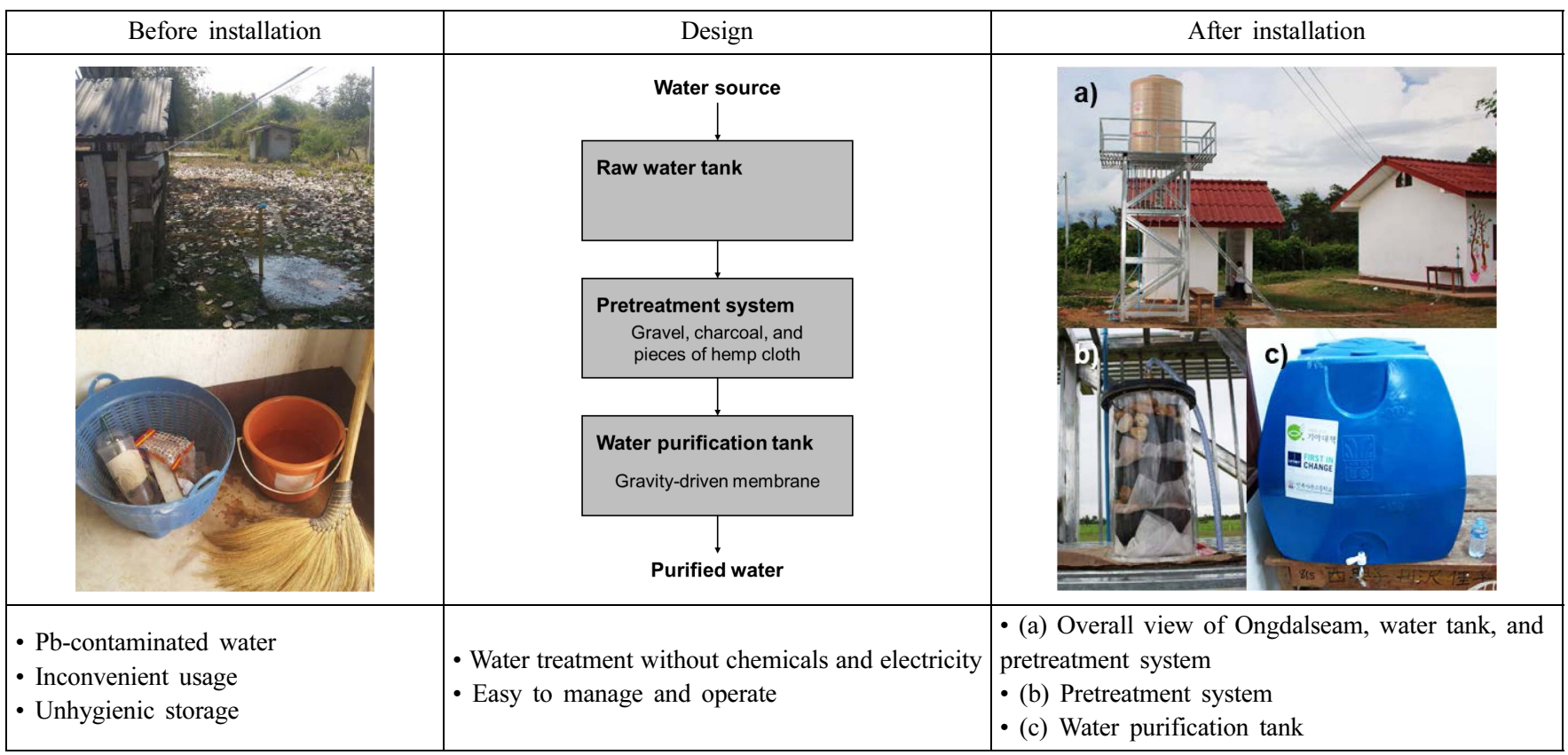
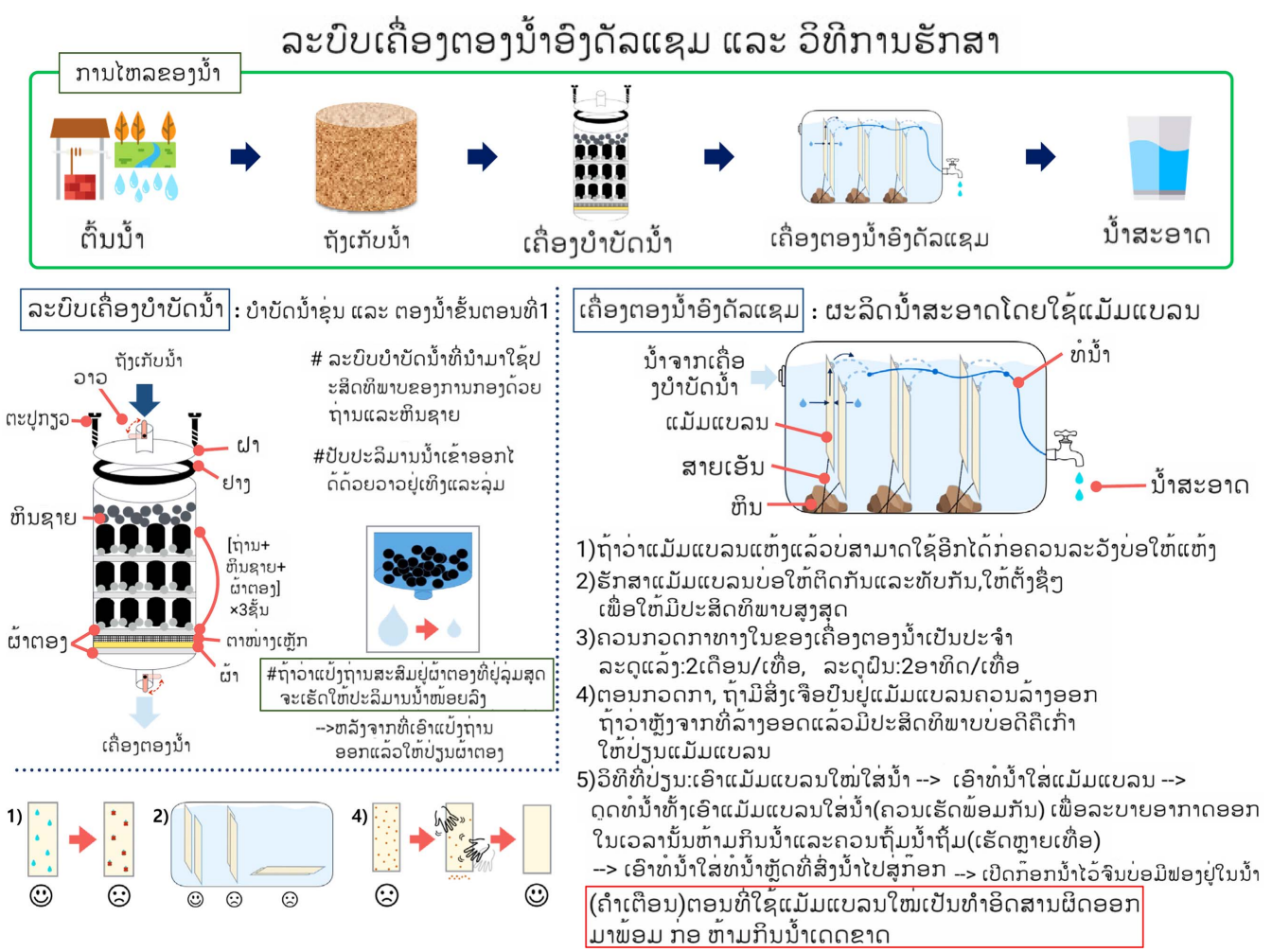

Figure 2. Manual for Ongdalsaem water purification system in Laotian.

at the onset of the dry season in November of 2017. W2 had originally been excluded at the first selection of a raw water source due to its high $\mathrm{Pb}$ concentration, but the raw water source inevitably had to change to W2 to secure water quantity. Due to the change in the raw water source, there was a concern about water quality again, so additional water quality 
Table 3. Results of first post-installation water quality analysis in September, 2017 with house well (W3) as raw water

\begin{tabular}{|c|c|c|c|c|}
\hline Parameters & $\begin{array}{l}\text { Raw water } \\
\text { (W3-R) }\end{array}$ & $\begin{array}{c}\text { First treated water } \\
\text { (W3-1) }\end{array}$ & $\begin{array}{l}\text { Final treated water } \\
\text { (W3-F) }\end{array}$ & $\begin{array}{l}\text { Drinking Water } \\
\text { Standard }^{\mathrm{a}}\end{array}$ \\
\hline $\mathrm{DOC}(\mathrm{mg} \mathrm{C} / \mathrm{L})$ & 0.19 & 0.27 & 0.27 & - \\
\hline $\mathrm{TN}(\mathrm{mg} \mathrm{N} / \mathrm{L})$ & 0.25 & 0.15 & 0.09 & - \\
\hline UVA254nm & 0.0032 & 0.0032 & 0.0042 & - \\
\hline SUVA & 1.668 & 1.191 & 1.551 & - \\
\hline $\mathrm{pH}$ in lab & 6.44 & 6.01 & 6.49 & $5.8-8.5$ \\
\hline Conductivity $(\mu \mathrm{S} / \mathrm{cm})$ & 42.94 & 20.03 & 43.20 & - \\
\hline $\mathrm{NH}_{4}{ }^{+}-\mathrm{N}(\mathrm{mg} / \mathrm{L})$ & N.D. & N.D. & N.D. & $<0.5 \mathrm{mg} / \mathrm{L}$ \\
\hline $\mathrm{NO}_{3}{ }^{-}-\mathrm{N}(\mathrm{mg} / \mathrm{L})$ & 0.20 & N.D. & N.D. & $<10 \mathrm{mg} / \mathrm{L}$ \\
\hline E. coli $(/ 100 \mathrm{~mL})$ & N.D. & N.D. & N.D. & N.D./100 mL \\
\hline $\mathrm{Pb}(\mathrm{mg} / \mathrm{L})$ & $\mathbf{0 . 0 2 2}^{\dagger}$ & $0.017^{\dagger}$ & N.D. & $<0.01 \mathrm{mg} / \mathrm{L}$ \\
\hline As $(\mathrm{mg} / \mathrm{L})$ & N.D. & N.D. & N.D. & $<0.01 \mathrm{mg} / \mathrm{L}$ \\
\hline $\mathrm{Hg}(\mathrm{mg} / \mathrm{L})$ & N.D. & N.D. & N.D. & $<0.001 \mathrm{mg} / \mathrm{L}$ \\
\hline $\mathrm{Cr}(\mathrm{mg} / \mathrm{L})$ & N.D. & N.D. & N.D. & $<0.05 \mathrm{mg} / \mathrm{L}$ \\
\hline $\mathrm{Cd}(\mathrm{mg} / \mathrm{L})$ & N.D. & N.D. & N.D. & $<0.005 \mathrm{mg} / \mathrm{L}$ \\
\hline $\mathrm{Cu}(\mathrm{mg} / \mathrm{L})$ & 0.012 & 0.018 & 0.026 & $<1 \mathrm{mg} / \mathrm{L}$ \\
\hline $\mathrm{Zn}(\mathrm{mg} / \mathrm{L})$ & 0.031 & 0.037 & 0.089 & $<3 \mathrm{mg} / \mathrm{L}$ \\
\hline $\mathrm{Fe}(\mathrm{mg} / \mathrm{L})$ & N.D. & N.D. & N.D. & $<0.3 \mathrm{mg} / \mathrm{L}$ \\
\hline $\mathrm{Mn}(\mathrm{mg} / \mathrm{L})$ & 0.027 & 0.041 & 0.006 & $<0.3 \mathrm{mg} / \mathrm{L}$ \\
\hline $\mathrm{Al}(\mathrm{mg} / \mathrm{L})$ & N.D. & N.D. & N.D. & $<0.2 \mathrm{mg} / \mathrm{L}$ \\
\hline
\end{tabular}

${ }^{a}$ Korean Ministry of Environment

- means not applicable.

N.D. means not detected.

'means unsuitable according to the standards for potable water.

analyses were carried out in January of 2018 (Table 4). In particular, the problematic $\mathrm{Pb}(0.007 \mathrm{mg} / \mathrm{L})$ was detected in the final treated water (W2-F) although it was below the standard. Therefore, it is necessary to find ways to use R1 as an alternative to secure the safest raw water source with enough quantity. Besides, alternatives should be prepared in advance to counteract unexpected variables at the site.

\section{BeeVi toilet}

A two-story BeeVi toilet cabin was constructed for Hatphain elementary school according to the toilet design (Table 5). A user enters the toilet space on the second floor and faces the handbasin first. When the interior door is opened, there is a non-flushing toilet separating feces and urine. After excretion, the user spreads sawdust or straw on the feces that are gathered in a wagon on the first floor. Urine is collected in a separate urine container on the first floor. Finally, the user washes his/ her hands in the handbasin. When the wagon is full of feces and sawdust, the mixture is moved to a composting area to ensure rapid and aerobic compost. Human manure is beneficial to replenish soil organic matter (SOM) which is a significant part of soil quality. SOM enhances soil activities in terms nutrient storage, ion exchange, water filtration and compaction control (Park et al., 2019; Zhang \& Schroder, 2014). This provides the effective microbial soil environments with macroand micronutrients, and promotes a plant growth (Chauhan et al., 2012; Tiwari et al., 1989). Besides, urine is also effective manure due to the urea found in urine which is absorbed by microorganisms and then absorbed by plants. Especially, it has the advantage of suppressing soil acidification and supplying nitrogen nutrients (Medeiros et al., 2020). In addition, training was regularly conducted toward sustainable management by teachers and the activist. Regarding the natural environment, by using the BeeVi toilet, feces and urine are not discharged directly into nature, thus the toilet contributes to preventing problems such as groundwater contamination. 
Table 4. Results of second post-installation water quality analysis in January, 2018 with elementary school well (W2) as raw water

\begin{tabular}{|c|c|c|c|c|}
\hline Parameters & $\begin{array}{l}\text { Raw water } \\
\text { (W2-R) }\end{array}$ & $\begin{array}{l}\text { First treated water } \\
(\mathrm{W} 2-1)\end{array}$ & $\begin{array}{l}\text { Final treated water } \\
\text { (W2-F) }\end{array}$ & $\begin{array}{c}\text { Drinking Water } \\
\text { Standard }^{\mathrm{a}}\end{array}$ \\
\hline $\mathrm{DOC}(\mathrm{mg} \mathrm{C} / \mathrm{L})$ & 0.13 & 0.10 & 0.52 & - \\
\hline $\mathrm{TN}(\mathrm{mg} \mathrm{N} / \mathrm{L})$ & 0.24 & 0.22 & 0.29 & - \\
\hline UVA254nm & 0.0021 & 0.0019 & 0.0043 & - \\
\hline SUVA & 1.53 & 1.92 & 0.83 & - \\
\hline $\mathrm{pH}$ in lab & 6.2 & 6.0 & 6.6 & $5.8-8.5$ \\
\hline Conductivity $(\mu \mathrm{S} / \mathrm{cm})$ & 41.8 & 38.3 & 68.2 & - \\
\hline $\mathrm{NH}_{4}{ }^{+}-\mathrm{N}(\mathrm{mg} / \mathrm{L})$ & N.D. & N.D. & N.D. & $<0.5 \mathrm{mg} / \mathrm{L}$ \\
\hline $\mathrm{NO}_{3}{ }^{-}-\mathrm{N}(\mathrm{mg} / \mathrm{L})$ & 0.26 & 0.25 & 0.21 & $<10 \mathrm{mg} / \mathrm{L}$ \\
\hline $\mathrm{Pb}(\mathrm{mg} / \mathrm{L})$ & $\mathbf{0 . 0 7 0}^{\dagger}$ & $\mathbf{0 . 0 5 2}^{\dagger}$ & 0.007 & $<0.01 \mathrm{mg} / \mathrm{L}$ \\
\hline As $(m g / L)$ & N.D. & N.D. & N.D. & $<0.01 \mathrm{mg} / \mathrm{L}$ \\
\hline $\mathrm{Hg}(\mathrm{mg} / \mathrm{L})$ & N.D. & N.D. & N.D. & $<0.001 \mathrm{mg} / \mathrm{L}$ \\
\hline $\mathrm{Cr}(\mathrm{mg} / \mathrm{L})$ & N.D. & N.D. & N.D. & $<0.05 \mathrm{mg} / \mathrm{L}$ \\
\hline $\mathrm{Cd}(\mathrm{mg} / \mathrm{L})$ & N.D. & N.D. & N.D. & $<0.005 \mathrm{mg} / \mathrm{L}$ \\
\hline
\end{tabular}

${ }^{a}$ Korean Ministry of Environment

- means not applicable.

N.D. means not detected.

'means unsuitable according to the standards for potable water.

Table 5. Processes showing BeeVi toilet installation

\begin{tabular}{|c|c|c|}
\hline Before installation & Design & After installation \\
\hline 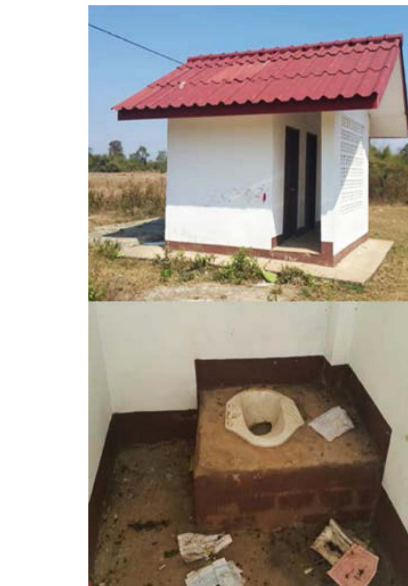 & 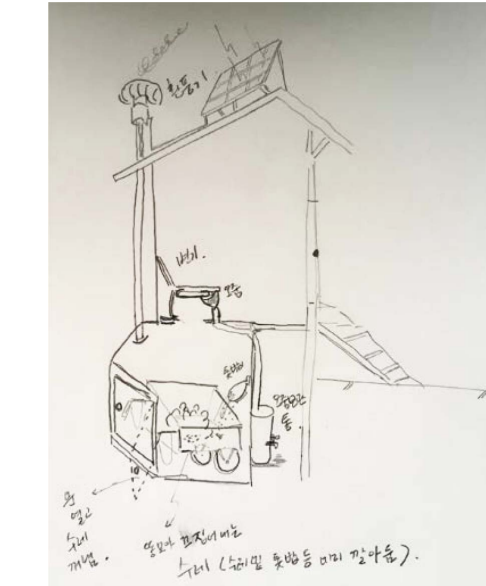 & (A) \\
\hline $\begin{array}{l}\text { - Only two toilets for } 66 \text { people } \\
\text { - One toilet was broken } \\
\text { - Inconvenient usage }\end{array}$ & $\begin{array}{l}\text { - Non-flushing toilet } \\
\text { - Separating feces and urine } \\
\text { - Added value without contamination }\end{array}$ & $\begin{array}{l}\text { - (a) View of toilet building } \\
\text { - (b) First floor } \\
\text { - (c) Toilet and sawdust } \\
\text { - (d) Feces-urine separating toilet }\end{array}$ \\
\hline
\end{tabular}

Our approach was connected with school farming by students and teachers themselves (Figure 3). The approach was aimed at increasing interest in using human originated manure and creating fun by growing fruit trees. By directly engaging with eco-friendly activities, people were able to naturally think about the importance of the environment and the connection of the environment with ourselves as a part of nature. Also, it is expected that these activities are beneficially linked with their family agriculture. 

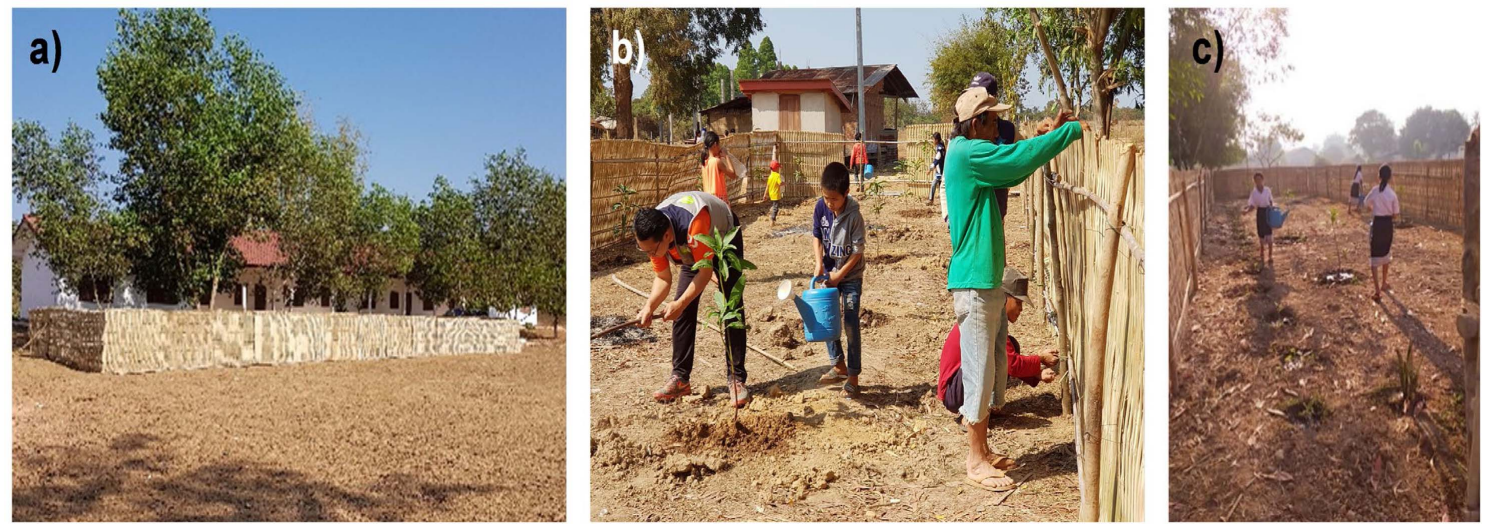

Figure 3. (a) A view of the school farm in Hatphain elementary school, (b) farming activities with students, teachers, and the activist, and (c) watering with urine manure by students.

\section{Application of feces Standard Money (fSM)}

Feces standard money (fSM) is a new complementary currency suggested by the Science Walden Research Center (UNIST) which is created based on the value of a person's feces when it is utilized in the form of energy or compost instead of
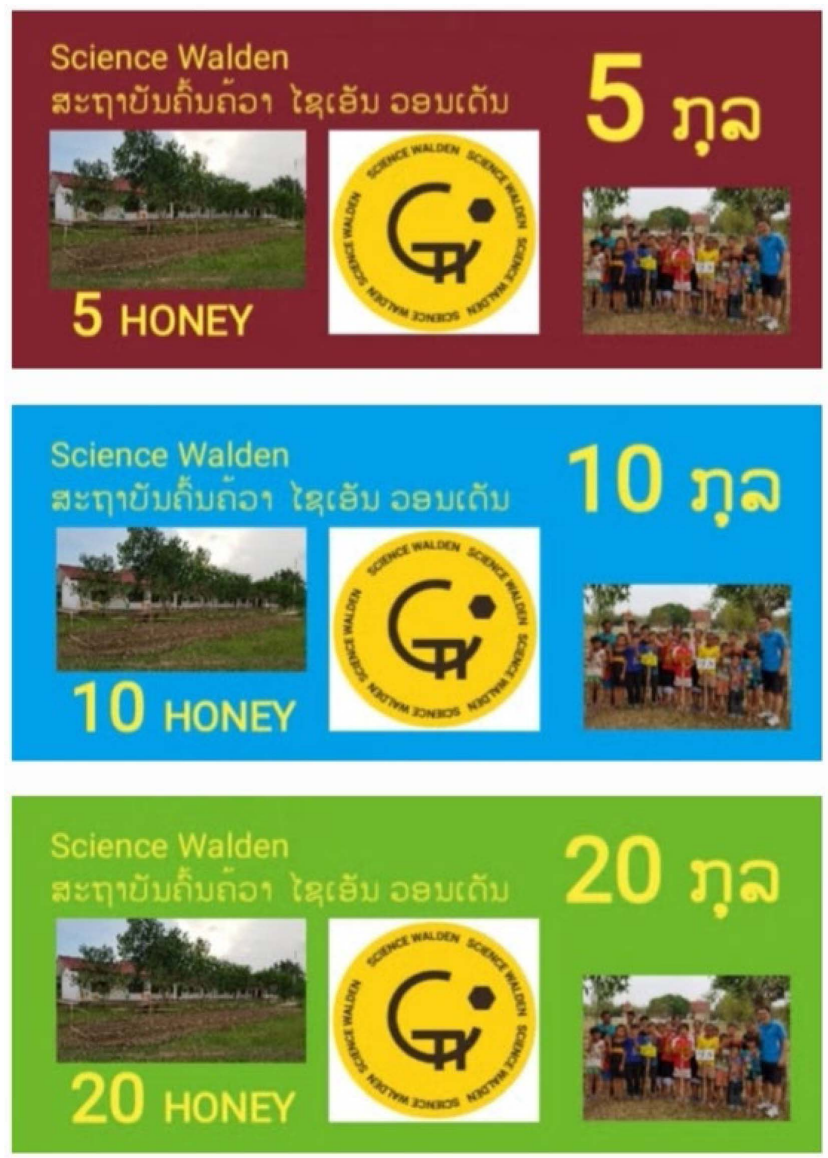

Figure 4. fSM notes used in Hatphain village. contaminating nature. Feces, which is treated as "bads", can be converted into "goods" such as biogas or compost. Also, producing feces is evidence of being alive. The value of fSM is created at this point. We defined the value of feces produced by one person in a day as 10 "Ggools," so that the price of other valuable items can be determined based on 10 Ggools. Ggool is a Korean word meaning "honey."

In Korea, fSM is circulated via an online platform (https:/ (fsm.network). However, fSM should be used as physical fSM money (Figure 4) made by the local activist because Hatphain village lacks Internet infrastructure and electricity to access the online platform. Therefore, an event, "Honey Market," was held to circulate fSM (Figure 5). Children used the BeeVi toilet and received fSM according to their accumulated score. We planned to help everyone better understand the circular economy through experience by purchasing products from the "Honey Market." Four shops were opened in the market, a school supplies shop, toy shop, confectionery shop, and beverage shop. By providing fSM to participating external children, parents, and village leaders, it provided an opportunity for understanding and participation in the project.

\section{Conclusion}

This study reports an on-going experiment relating to supporting self-sustainable village development by applying both appropriate environmental technologies and the fSM concept. The appropriate technologies, the water purifying system and eco-toilet, were directly applied at the elementary school in Hatphain village which is underdeveloped without 

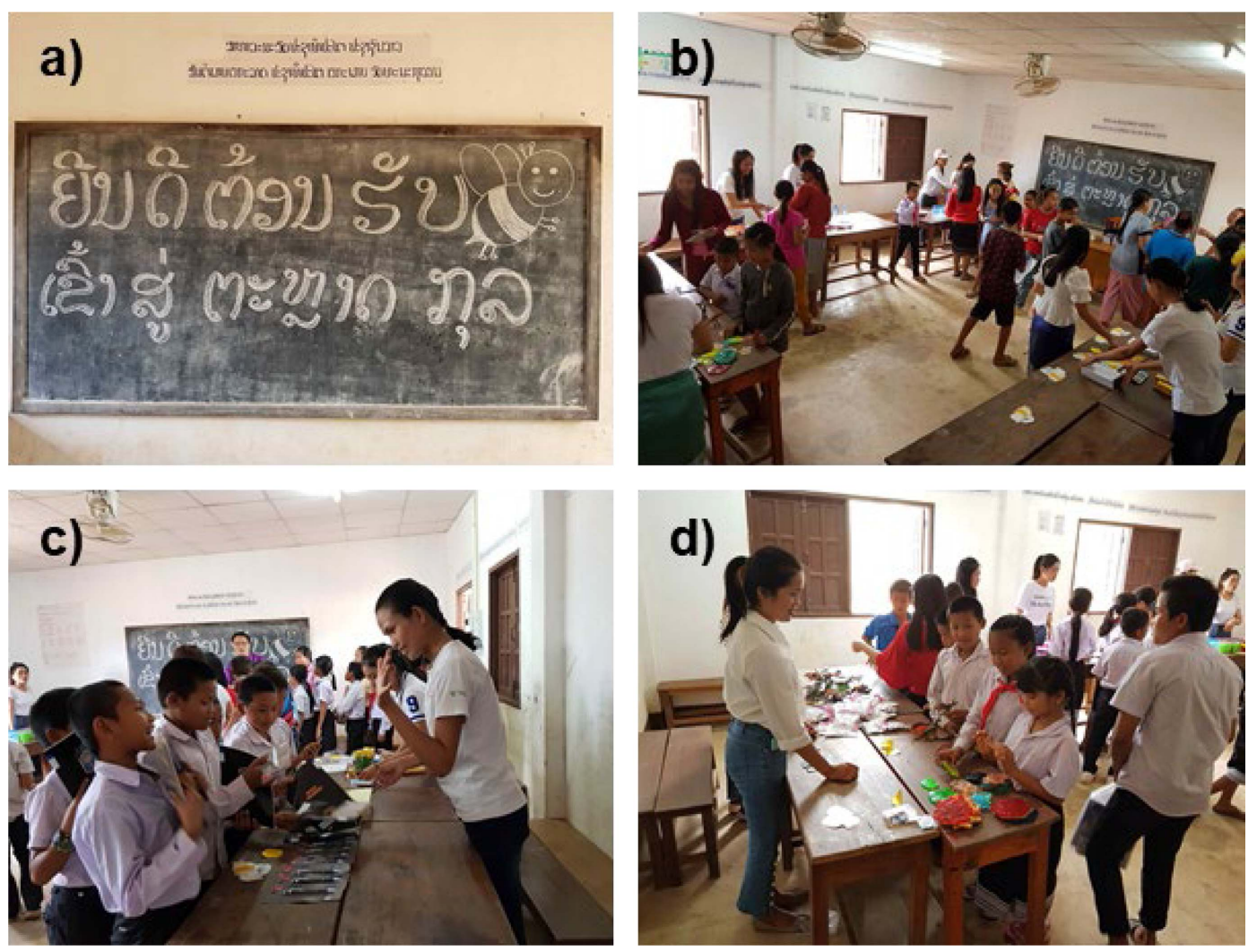

Figure 5. Photographs from the "Honey Market" (a) Welcome to "Honey Market" is written on the blackboard. (b)-(d) Photographs showing that students are using fSM.

access to clean water, a sewerage system, or power lines. Additionally, the quantity of water supplied by water sources is not enough or secure and contains problematic heavy metal ions, copper, nitrate, and ammonium ions. The water purifying system, Ongdalsaem does not use any power and works by connected gravity-driven membranes. The potable water produced via the two-step treatment was satisfactory according to standard guidelines for drinking water. The first filtered water could be accessed at a faucet in the schoolyard for handwashing and the second filtered water, purified using the membranes, was provided as drinking water at the same time. A total of 624 persons including students, teachers, and local residents have benefited by utilizing the safe drinking water from Ongdalsaem. Besides, by providing a more comfortable and cleaner toilet place, students and teachers can feel safe. Furthermore, the direct discharge of feces and urine into nature is prevented.

There are several reasons that this project has been sustained thus far. First, managers of the Ongdalsaem, BeeVi toilet, and farms were chosen and given the responsibility to train others and operate on their own. Second, the installation of the technologies worked simultaneously with the children's storytelling program and art play to reduce their resistance to new things rather than adopting a unilateral education approach. Even though the research team has left, they are still conducting maintenance and operation training through the local activist who can communicate directly with the research team. By communication, various cases that relate research results, and sharing practical activities that are being carried out in Korea there has been a significant bonding experience. Also, the research team visits every year not only to monitor but also to provide educational opportunities.

We strived to spread the new concept of an environmentally self-sustainable village with cultivation culture using human originated manure, new experiences on eco-circulation, and learning naturally about environmental technology and microbiology through practical and playing facilities. The indirect experience of the circular economy and the valuable outcomes were created by students themselves through fSM so that they could organically learn about the environment and related 
economic activities. Although fSM is a type of virtual currency in Korea, we implemented and experimented with actual fSM money in Hatphain village to suit the social infrastructure available there. This can be linked to an offline fSM experiment in communities in Korea in the future. Despite our efforts, repairs of the toilet facilities are constantly needed due to the effects of torrential rainfall and lack of consciousness. Continuous support of the local activist is still being maintained based on the feedback of students who are the actual users.

\section{Acknowledgments}

We sincerely thank Mr. Joseph Oh at World Vision. This work was supported by the National Research Foundation of Korea (NRF) Grand funded by the Korean Government (MSIT) (No.: NRF-2015R1A5A7037825 \& NRF-2017K1A3A9A01013898).

\section{References}

Bamberger, M. (1991). The importance of community participation. Public Administration and Development, 11(3), 281-284.

Chauhan, B. S., Singh, R. G., and Mahajan, G. (2012). Ecology and management of weeds under conservation agriculture: a review. Crop Protection, 38, 57-65.

Cho, J. (2017). Feces Standard Money (FSM). Know This: Today's Most Interesting and Important Scientific Ideas, Discoveries, and Developments (Edge Question Series), J. Brockman (Ed.), Harper Perennial. N.Y., USA, pp. 338-339.

Chowdhury, S., Mazumder, M. J., Al-Attas, O., and Husain, T. (2016). Heavy metals in drinking water: occurrences, implications, and future needs in developing countries. Science of the total Environment, 569, 476-488.

Davidson, C. H., Johnson, C., Lizarralde, G., Dikmen, N., and Sliwinski, A. (2007). Truths and myths about community participation in post-disaster housing projects. Habitat international, 31(1), 100-115.

Frandsen, V. LifeStraw (2005). https://www.vestergaard.com/ lifestraw/ (accessed Apr. 2021)

Jakariya, M., Iqbal, S., Dastidar, N., and Sujauddin, M. (2018).
Application of sustainable energy paradigm through solar bottle light: A case study from Dhaka, Bangladesh The Environmental Sustainable Development Goals in Bangladesh (pp. 59-70): Routledge.

Medeiros, D. L., Queiroz, L. M., Cohim, E., de Almeida-Neto, J. A., and Kiperstok, A. (2020). Human urine fertiliser in the Brazilian semi-arid: Environmental assessment and waterenergy-nutrient nexus. Science of The Total Environment, 713, 136-145.

Murphy, H. M., McBean, E. A., and Farahbakhsh, K. (2009). Appropriate technology-A comprehensive approach for water and sanitation in the developing world. Technology in Society, 31(2), 158-167.

Park, J., Cho, K. H., Ligaray, M., and Choi, M. J. (2019). Organic Matter Composition of Manure and Its Potential Impact on Plant Growth. Sustainability, 11(8).

Patnaik, J., and Bhowmick, B. (2019). Revisiting appropriate technology with changing socio-technical landscape in emerging countries. Technology in Society, 57, 8-19.

Shin, H., Hwang, J., and Kim, H. (2019). Appropriate technology for grassroots innovation in developing countries for sustainable development: The case of Laos. Journal of Cleaner Production, 232, 1167-1175.

Sorlini, S., Rondi, L., Pollmann Gomez, A., and Collivignarelli, C. (2015). Appropriate Technologies for Drinking Water Treatment in Mediterranean Countries. Environmental Engineering \& Management Journal (EEMJ), 14(7), 1721-1733.

Tiwari, S. C., Tiwari, B. K., and Mishra, R. R. (1989). Microbial populations, enzyme activities and nitrogen-phosphoruspotassium enrichment in earthworm casts and in the surrounding soil of a pineapple plantation. Biology and Fertility of Soils, 8(2), 178-182.

Vinnerås, B., Hedenkvist, M., Nordin, A., and Wilhelmson, A. (2009). Peepoo bag: self-sanitising single use biodegradable toilet. Water Science and Technology, 59(9), 1743-1749.

Zhang, H., and Schroder, J. (2014). Animal manure production and utilization in the US Applied manure and nutrient chemistry for sustainable agriculture and environment (pp. 1-21): Springer. 